\title{
Guideline-orientated Diagnosis of Thyroid Nodules
}

\author{
Ralf Paschke, ${ }^{1}$ Enrico Papini ${ }^{2}$ and Hossein Gharib ${ }^{3}$
}

1. Professor of Internal Medicine and Endocrinology, III Medical Department, University of Leipzig; 2. Professor of Endocrinology, University of Rome

'La Sapienza' Medical School; 3. Professor of Medicine, Division of Endocrinology, Diabetes, Metabolism and Nutrition, Mayo Clinic College of Medicine

DOI: 10.17925/USE.2009.05.1.59

\begin{abstract}
Thyroid nodules are very common. Their aetiology is due to the interaction between genetic and environmental factors. In 2006, two major society-sponsored guidelines and one major consensus statement for thyroid diagnosis and management were published by the American Association of Clinical Endocrinologists/Associazione Medici Endocrinologi (AACE/AME), the American Thyroid Association (ATA) and the European Thyroid Association (ETA). A careful review of these guidelines reveals that despite many similarities, significant differences are also present, likely reflecting differences in practice patterns, interpretation of existing data and availability of resources in different regions. The methodology of the guidelines is similar, but a few differences in the rating scales make a rapid comparison of the strength of both evidence and recommendations difficult for use in current clinical practice. Some recommendations are based mostly on expert opinion. The same recommendation may be based on different evidence; on the other hand, sometimes the same evidence may induce a different recommendation. A survey performed during an interactive symposium at the 32nd annual meeting of the ETA in Leipzig, Germany, was carried out to investigate whether these guidelines were able to affect the divergent management strategies for thyroid nodules that have previously been documented. The thyroid nodule guidelines obviously provide useful information and recommendations for practice and have a positive impact on patient care; however, guidelines should be considered as suggestions rather than a rigid formula for practice. With further accumulating evidence, these guidelines will need revision and updating.
\end{abstract}

\section{Keywords}

Thyroid nodule, diagnosis, treatment, guidelines, evidence-based

Disclosure: The authors have no conflicts of interest to declare.

Received: 27 April 2009 Accepted: 10 July 2009

Correspondence: Ralf Paschke, III Medical Department, University of Leipzig, Ph.-Rosenthal-Str. 27, D-04103 Leipzig, Germany. E: pasr@medizin.uni-leipzig.de

\section{Aetiology, Epidemiology and Risks}

Thyroid nodules are very common. Moreover, with the increasing use of sensitive imaging techniques, an increasing proportion of thyroid nodules are now detected incidentally. A prospective study comparing clinical examination and ultrasound showed that $46 \%$ of nodules $>1 \mathrm{~cm}$ detected by ultrasound escaped detection by clinical examination. ${ }^{1}$ Autopsy and prospective ultrasound studies in North America detected asymptomatic thyroid nodules in 50 and $67 \%$, respectively. ${ }^{2,3} \mathrm{~A}$ population study in Germany - a previously iodinedeficient and currently borderline iodine-sufficient country detected thyroid nodules by ultrasound in $20 \%$ of the population 20-79 years of age. The prevalence increased with advancing age to 52 and $29 \%$, respectively, for women and men $70-74$ years of age. ${ }^{4}$

According to current knowledge, the aetiology of thyroid nodules can be summarised as outlined in Figure 1 (modified from Krohn et al. ${ }^{5}$ and Krohn et al. ${ }^{\circ}$ ). Susceptibility to developing a thyroid nodule or goitre mainly in response to iodine deficiency is genetically determined. In genetically susceptible individuals with maladaptation to iodine deficiency, the increased thyroid epithelial cell proliferation and the increased production of $\mathrm{H}_{2} \mathrm{O}_{2}$ will lead to an increased rate of mutagenesis; depending on which gene is hit, this will lead to small clones of hot or cold thyroid cells, which will then give rise to hot or cold thyroid nodules or, less frequently, thyroid carcinomas.
In areas not affected by nuclear fall-out, the annual incidence of thyroid cancer has been reported to range between 1.2 and 2.6 cases per 100,000 in men and 2.0 and 3.8 cases per 100,000 in women, with higher incidences in countries such as Sweden, France, Japan and the US. ${ }^{7}$ An increase of thyroid cancer incidence from 3.6 per 100,000 in 1973 to 8.7 per 100,000 in 2002 has recently been reported in the US. ${ }^{8}$ A similar increase of thyroid cancer incidence from 1983 to 2000 was reported in France, ${ }^{9}$ and the incidence of thyroid cancer in Germany in 2002 was 6.7 and 3.2 per 100,000 women and men, respectively. ${ }^{10}$ However, most of these increases in thyroid cancer incidence are due to an increased detection of small papillary cancers. ${ }^{8,9}$

In autopsy studies, clinically silent thyroid papillary microcarcinomas ( $<1 \mathrm{~cm}$ diameter) have been reported in up to $36 \%$ depending on the number of serial sections. ${ }^{11}$ Most autopsy studies report incidences ranging from 6 to $11 \% .{ }^{12-14}$ A comparison of these papillary microcarcinoma incidence rates in autopsy studies with the incidence rates for clinically apparent papillary carcinomas strongly suggests that most papillary microcarcinomas will not lead to clinically apparent thyroid carcinomas. Moreover, these data suggest that histological evaluation of resected thyroid tissue will often detect papillary microcarcinomas with an unlikely clinical relevance. A follow-up study of papillary microcarcinomas over a nine-year period demonstrated no metastases in patients with tumours $<0.8 \mathrm{~mm} .{ }^{15}$ 


\section{Figure 1: lodine Deficiency}

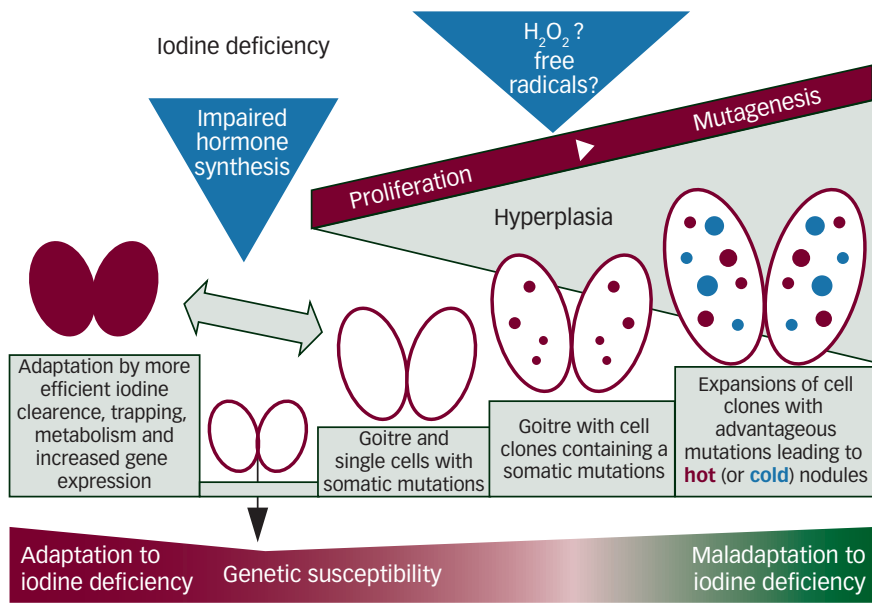

According to current knowledge, 5,6 the aetiology of thyroid nodules can be summarised as follows: in genetically susceptible individuals with maladaptation to iodine deficiency, the increased thyroid epithelial cell proliferation and the increased production of $\mathrm{H}_{2} \mathrm{O}_{2}$ will lead to an increased rate of mutagenesis; depending on the gene that is hit, this will lead to small clones of hot or cold thyroid cells, which will then give rise to hot or cold thyroid nodules or, less frequently, thyroid carcinomas.

Source: Krohn et al., $2005^{5}$ and Krohn et al., 2007. ${ }^{\circ}$

Studies on the epidemiology of thyroid nodule function are rare. The scintigraphic evaluation of $60 \%$ of the solitary nodules detected by ultrasound in a random cohort of probands 41-71 years of age living in an area with borderline iodine deficiency revealed cold nodules in $46 \%$, isofunctioning nodules in $44 \%$ and hot nodules in $6 \% .{ }^{16}$ In another population study, thyroid nodules were detected by thyroid palpation of adults 18-64 years of age in only $1.9 \%$ in an iodine-sufficient area and in $5.1 \%$ in an iodine-deficient area. The scintigraphic evaluation of these nodules identified cold nodules in 87 and $84 \%$, isofunctioning nodules in 0.4 and $0.6 \%$ and hot nodules in 8 and $10 \%$ in the iodine-sufficient and iodine-deficient areas, respectively. ${ }^{17}$ Most hot nodules are easily detected by thyroidstimulating hormone (TSH) determination; however, in iodinedeficient areas scintigraphic evidence of thyroid autonomy has been reported in $40 \%$ of patients with euthyroid endemic goitres. ${ }^{18}$ Moreover, somatic constitutively activating TSH receptor mutations have been detected in small 131-iodine (131) hypercaptant areas detected by autoradiography. ${ }^{19}$ It is therefore likely that not all hot nodules - which are much more frequent in iodine-deficient than in iodine-replete areas $^{20}$ - are detectable by determination of TSH. However, if the hot nodule volume surpasses $16 \mathrm{ml}$, a suppressed TSH was detectable with a TRH test even with older radioimmunoassay (RIA) technology. ${ }^{21}$ Obviously, the critical threshold volume of hot nodules that will lead to TSH suppression needs to be re-evaluated using a third-generation TSH assay.

The high prevalence of thyroid nodules requires rational evidencebased strategies for their differential diagnosis, risk stratification, treatment and follow-up. These strategies should concentrate on the risk of malignancy, hyperthyroidism and symptoms and should be adaptable to the wide spectrum of clinical manifestations of thyroid nodules, ranging from small $(<1 \mathrm{~cm})$ thyroid incidentaloma to large symptomatic thyroid nodules with progressive growth. Moreover, these strategies should also account for the different prevalences of thyroid nodules, hot nodules and the different subtypes of differentiated thyroid carcinomas in iodine-replete and iodine-deficient areas, as well as different healthcare systems.

\section{Evolution of Diagnostic Strategies for Thyroid Nodules}

Several questionnaire studies with European, North American and Australian endocrinologists repeatedly revealed large discrepancies in the diagnosis and management of thyroid nodules. ${ }^{22-25}$ Among other discrepancies, a less frequent application of fine-needle aspiration biopsy (FNAB) and more frequent use of thyroid scintigraphy, thyroid ultrasound calcitonin and thyroid peroxidase (TPO) antibody determination for the diagnosis of thyroid nodules in Europe compared with North America and different strategies for the treatment of thyroid nodules became apparent. Most of these questionnaires - and especially those performed in Europe and North America - were published in 1999 and 2000; that is, before the three major society-sponsored guidelines for thyroid diagnosis and management were published: by the American Association of Clinical Endocrinologists/Associazione Medici Endocrinologi (AACE/ AME), the American Thyroid Association (ATA) and the European Thyroid Association (ETA). ${ }^{26-28}$

One survey performed during an interactive symposium at the 32nd annual meeting of the ETA in Leipzig, Germany, was carried out to investigate whether these guidelines were able to affect the divergent management strategies for thyroid nodules that have previously been documented. ${ }^{29}$ This survey showed that for a standard patient, i.e. a 40-year-old woman with a recently discovered asymptomatic easily palpable, firm, solitary $2.5 \mathrm{~cm}$ right thyroid nodule with no cervical adenopathy, 90\% of the European thyroid specialists would perform a thyroid ultrasound. If her serum TSH was $0.6 \mathrm{mIU} / \mathrm{I}$ (normal $0.5-4.5$ ), $45 \%$ would obtain a radioisotope scan, $42 \%$ would not obtain one and $12 \%$ were undecided. Compared with previous European surveys, ${ }^{23,25,26}$ these results demonstrate an increased use of thyroid ultrasound and a decreased use of scintigraphy by European thyroid experts. Moreover, in evaluating thyroid nodules, ATA members use imaging less often than their ETA colleagues, and ATA respondents used thyroid scan less frequently and ultrasound more frequently in 2000 compared with $1996 .{ }^{30}$

\section{The high prevalence of thyroid}

nodules requires rational evidence-

based strategies for their differential

diagnosis, risk stratification, treatment

and follow-up.

Concordance between guidelines is very high for both the clinical recommendations and the grade of their strength, but the evidence available for recommending ultrasound examination is correctly reported only as fair (ATA: grade B; AACE/AME: grade C). Indeed, although ultrasound is generally appreciated as a diagnostic procedure that induces a powerful effect on thyroid outcomes, the quality of evidence-based medicine (EBM) evidence in favour of clinical use of ultrasound thyroid scan may be rated just as fair due to the absence of level 1 and 2 clinical evidence.

The examination of the linked references confirms these remarks. For the thyroid ultrasound issue, the ATA reports three observational 
studies (level of evidence: 3 according to AACE scale), the ETA one retrospective observational study (level of evidence: 3 ) and one consensus (level of evidence: 4) and the AACE/AME five prospective observational studies (level of evidence: 3 ) and six reviews (level of evidence: 4). For FNAB, the ATA reports three observational studies (level of evidence: 3), the ETA three observational studies (level of evidence: 3) and one review (level of evidence: 4) and the AACE/AME six observational studies (level of evidence: 3 ) and seven reviews with a pooled analysis (level of evidence: $3-4$ ).

It is noteworthy to observe that the evidence reported by the ATA, the ETA and the AACE/AME guidelines on thyroid ultrasound and FNAB lacks consistency. The three guidelines share only:

- one reference in ATA and ETA (Marqusee et al. ${ }^{31}$ );

- two references in ATA and AACE/AME (Tan et al. ${ }^{32}$ and Hagag et al. $\left.{ }^{33}\right)$; and

- no references in the ETA Consensus and the AACE/AME GL.

With regard to the ability of thyroid ultrasound to predict malignancy, the recent consensus statement by radiologists documented low sensitivity and low specificity for all single ultrasound criteria, ${ }^{34}$ as outlined in Table 1. However, as suggested by several studies, most likely the combination of several ultrasound criteria together with clinical criteria suggestive of malignancy will lead to a better selection of thyroid nodules for FNAB. ${ }^{35,36}$

According to the ATA guidelines, in the presence of a low or low to normal serum TSH concentration, a radioiodine scan should be performed and directly compared with the ultrasound images to determine the functionality of each nodule larger than $1-1.5 \mathrm{~cm}$. The AACE/AME and the ETA extend the indication to radioisotope scan, suggesting that thyroid scintigraphy should be performed for a multinodular goitre in iodine-deficient areas even if the TSH level is still in the normal range in order to identify the presence of an autonomous nodule. Concordance between the guidelines is very high for the suggested actions even if the clinical evidence available for using radioisotope scan is just fair (ATA: grade $B$; AACE/AME: grade $\mathrm{B}$ and $\mathrm{C}$ ).

Literature linked to the issue of thyroid scintigraphy is scarce. The ATA guidelines quote no references, the ETA mentions one reference $\left(\mathrm{PaCini}^{{ }^{3}}{ }^{7}\right.$ ) and the AACE/AME reports seven articles (one review and six observational studies). In fact, the quality of EBM evidence about the use of radioisotope scans is quite low due to the absence of level 1 and 2 evidence, and at present recommendations are based mostly on expert opinion and largely accepted thyroid practice.

FNAB is currently the most sensitive and specific test to distinguish benign and malignant thyroid nodules (see Table 2). For the further work-up of the example patient mentioned above, $74 \%$ selected FNA with ultrasound guidance. This seems surprising, considering that the nodule was easily palpable. However, as the vast majority of European experts use ultrasound for the initial investigation of such patients, it appears logical that they would also perform an ultrasound-guided FNA rather than a palpation-directed FNA. Several recent reports suggest that ultrasound-FNA is more reliable than palpation-FNA. ${ }^{26,38}$ With the use of ultrasound guidance, the sensitivity, positive predictive value and negative predictive value of
Table 1: Ultrasound Characteristics Associated with Thyroid Cancer

\begin{tabular}{lllll}
$\begin{array}{l}\text { Ultrasound } \\
\text { Characteristics }\end{array}$ & $\begin{array}{l}\text { Sensitivity } \\
(\%)\end{array}$ & $\begin{array}{l}\text { Specificity } \\
(\%)\end{array}$ & $\begin{array}{l}\text { Positive } \\
\text { Predictive } \\
\text { Value (\%) }\end{array}$ & $\begin{array}{l}\text { Negative } \\
\text { Predictive } \\
\text { Value (\%) }\end{array}$ \\
$\begin{array}{llll}\text { Microcalcifications } \\
\text { 1-5 }\end{array}$ & $26-59$ & $86-95$ & $24-71$ & $42-94$ \\
\hline $\begin{array}{l}\text { Hypoechogenicity } \\
\text { I-5 }\end{array}$ & $27-87$ & $43-94$ & $11-68$ & $74-94$ \\
\hline $\begin{array}{l}\text { Irregular margins or } \\
\text { no halo }\end{array}$ & $17-78$ & $39-85$ & $9-60$ & $39-98$ \\
\hline $\begin{array}{l}\text { Solid } \\
\text { Intranodule }\end{array}$ & $69-75$ & $53-56$ & $16-27$ & $88-92$ \\
vascularity & $54-74$ & $79-81$ & $24-42$ & $86-97$ \\
\hline
\end{tabular}

The ability of single thyroid ultrasound criteria to predict malignancy has been summarised in the recent consensus statement by radiologists. It documented low sensitivity and low specificity for all single ultrasound criteria. ${ }^{34}$

Table 2: Summary of Characteristics for Thyroid Fine-needle Aspiration

\begin{tabular}{|c|c|c|c|}
\hline Feature & Mean (\%) & Range (\%) & Definition \\
\hline Sensitivity & 83 & 65-98 & $\begin{array}{l}\text { Likelihood that patient with disease } \\
\text { has positive test results }\end{array}$ \\
\hline Specificity & 92 & $72-100$ & $\begin{array}{l}\text { Likelihood that patient without } \\
\text { disease has negative test results }\end{array}$ \\
\hline $\begin{array}{l}\text { Positive } \\
\text { predictive value }\end{array}$ & 75 & $50-96$ & $\begin{array}{l}\text { Fraction of patients with positive test } \\
\text { results who have disease }\end{array}$ \\
\hline $\begin{array}{l}\text { False-negative } \\
\text { rate }\end{array}$ & 5 & $1-11$ & $\begin{array}{l}\text { Fine-needle aspiration negative; } \\
\text { histology positive for cancer }\end{array}$ \\
\hline $\begin{array}{l}\text { False-positive } \\
\text { rate }\end{array}$ & 5 & $0-7$ & $\begin{array}{l}\text { Fine-needle aspiration positive; } \\
\text { histology negative for cancer }\end{array}$ \\
\hline
\end{tabular}

Fine-needle aspiration biopsy is currently the most sensitive and specific test to distinguish benign and malignant thyroid nodules. ${ }^{26}$

the test increase significantly. Accordingly, as the use of thyroid ultrasound by endocrinologists is becoming more widespread, the AACE/AME guidelines suggest ultrasound FNA in the following clinical settings: any size nodule with a history of radiation, family history of mycobacterium tuberculosis complex (MTC) or family history of multiple endocrine neoplasia type 2 (MEN2); any size nodule with suspicious ultrasound features; nodules with extracapsular growth or cervical nodes; and impalpable or small $(<1 \mathrm{~cm})$ nodule. The other two guidelines do not make specific recommendations for ultrasound-FNA.

If the FNA result is benign, 59 and $27 \%$ would ask this patient to return in six to 12 months for thyroid palpation + ultrasound or thyroid palpation + ultrasound + FNA, respectively. The AACE/AME guidelines suggest simple follow-up for cytologically benign thyroid nodules; repeat ultrasound was not recommended. The ATA guidelines suggest clinical follow-up at six to 18 months, without ultrasound monitoring, for easily palpable benign nodules. Opinion on re-aspiration of benign nodules remains divided. The AACE/AME suggests re-aspiration only for enlarging nodules, recurrent cysts or nodules not shrinking after T4 therapy; the ATA guidelines suggest either re-aspiration or surgery for growing nodules. Wiersinga has recommended repeat palpation and FNA one year after a benign FNA result. ${ }^{39}$ Lucas et al. re-biopsied 116 patients with benign FNA and found no missed malignancy, concluding that re-aspiration is not necessary. ${ }^{40}$ On the other hand, Chehade et al. followed 235 patients with benign FNA for an average of 2.9 years, and on repeat FNA found malignancy in one $(0.4 \%)$, concluding that re-biopsy reduces false-negative rates. ${ }^{41}$ 
Figure 2: Flow Chart for the Diagnostic Evaluation of Thyroid Nodules

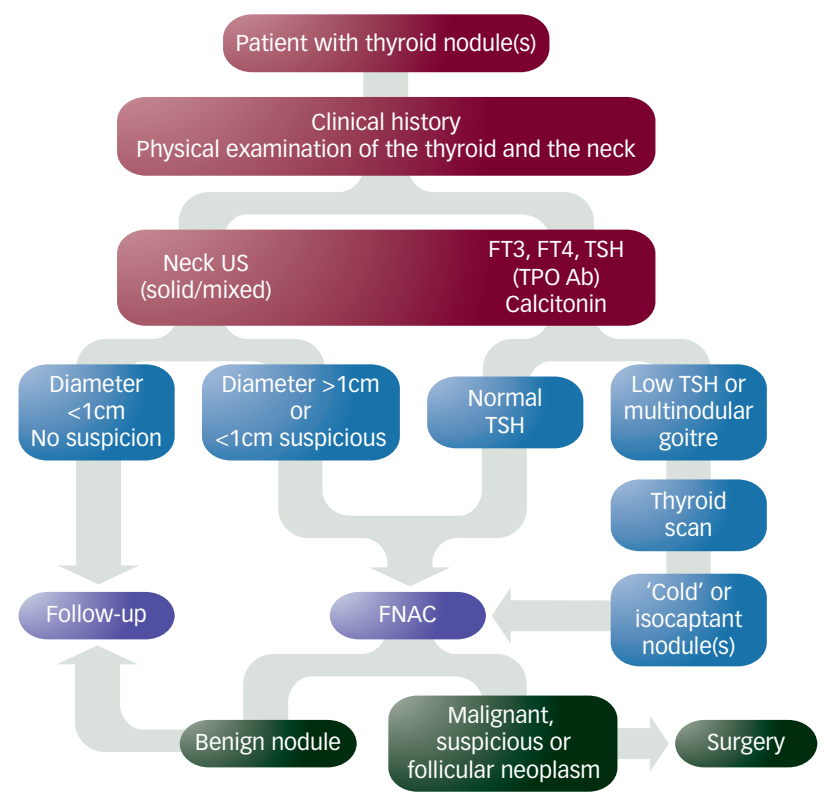

This figure presents an attempt at an overview that tries to give an integrated view of the diagnostic approaches for the diagnostic workup of a patient with a thyroid nodule.

FNAC = fine-needle aspiration cytology; TPO Ab = thyroid peroxidase antibody;

TSH = thyroid-stimulating hormone: US = ultrasound

Source: Pacini F, Schlumberger $M$, Dralle $H$, et al. ${ }^{28}$

\section{Table 3: Factors Suggesting Increased Risk of Malignancy}

History of head and neck irradiation

Family history of MTC or MEN2

Age $<20$ or $>70$ years

Male sex

Growing nodule

Firm or hard consistency

Cervical adenopathy

Fixed nodule

Persistent hoarseness, dysphonia, dysphagia or dyspnoea

MEN2 = multiple endocrine neoplasia type 2: MTC = mycobacterium tuberculosis complex Source: American Association of Clinical Endocrinologists and Associazione Medici Endocrinologi, 2006. ${ }^{20}$

For the example patient - a 40-year-old woman with a single $2.5 \mathrm{~cm}$ nodule that is benign, colloid by FNA and solid by ultrasound and with serum TSH $0.6 \mathrm{mIU} / \mathrm{I}$ - 65\% would not recommend T4 suppressive therapy. Whereas previously most endocrinologists would have used T4 to suppress TSH in this case, current guidelines do not recommend this practice. Therefore, it is gratifying that $65 \%$ of the European thyroid specialists agreed with the guidelines and chose not to use T4 therapy. The AACE/AME guidelines state that routine T4 therapy in patients with benign thyroid nodules is not appropriate, but it may be considered in iodine deficiency. Only $12 \%$ of this group voted to use T4 if the patient was in an iodine-deficient area. The ATA guidelines do not recommend suppression therapy for benign nodules. A recent meta-analysis of nine studies including 596 patients showed that nodule volume decreased significantly in only fewer than $20 \%$ of the treated group. Moreover, T4 suppressive therapy led to a non-significant improvement in the rate of response to therapy (defined as $\geq 50 \%$ nodule volume reduction by ultrasound): pooled relative risk (RR) 1.83 95\% confidence interval (Cl) $0.9-3.73 .{ }^{42}$ In summary, neither the guidelines nor the majority of European thyroid specialists recommend $\mathrm{T} 4$ to suppress benign thyroid nodules.
If cytology showed 'suspicious for malignancy - follicular neoplasm', $80 \%$ would recommend surgical excision of the nodule. Management of a nodule with indeterminate cytology still generates controversy. The cancer risk among these specimens ranges from 15 to $75 \%$, and is approximately $15 \%$ for follicular neoplasms. Immunohistochemica markers have neither regularly nor reliably separated benign from malignant lesions. ${ }^{38}$ Repeat biopsy is not helpful and can even lead to confusion, because if re-aspiration is benign, the clinician has to reconcile between a benign and a suspicious result. The AACE/AME guidelines consider surgical excision as the best management; repeat biopsy or large-needle biopsy is not recommended. The ATA guidelines discourage the use of molecular markers and prefer a radioiodine thyroid scan to rule out nodule hyperfunction when cytology is suspicious. The ETA guidelines find immunocytochemistry neither sensitive nor specific, believing surgical treatment is the best approach.

If the cytology is 'follicular neoplasm', lobectomy and post-operative histological review was recommended by $24 \%$, near-total thyroidectomy by $34 \%$ and lobectomy and intraoperative frozen section exam by $36 \%$ of the European thyroid specialists. The AACE/AME guidelines recommend surgical treatment but do not specify the extent of surgery. The ATA guidelines suggest thyroid lobectomy for an isolated, indeterminate solitary nodule, whereas the ETA recommends lobectomy for a solitary nodule and a near-total thyroidectomy for a multinodular goitre when cytology is suspicious. Moreover, the ETA does not endorse frozen section because of the high frequency of false-negative results.

Several recent reports suggest that in experienced hands intraoperative frozen section can accurately separate benign from malignant follicular or Hurthle cell neoplasms. For example, Paphavasit and colleagues report that intraoperative frozen section was correct in $78 \%$ of patients, with sensitivity, specificity, positive predictive value, negative predictive value and accuracy of $78,99,90$, 98 and $98 \%$, respectively. ${ }^{43}$ It is therefore not surprising that European thyroid experts seem evenly divided between the surgical options noted above. While there is no majority of opinion here, these differences likely represent the availability of surgical and pathology expertise available to each participant in his/her clinic or location.

For the example patient, $49 \%$ of the European thyroid specialists would measure a baseline serum calcitonin (CT) level, whereas $43 \%$ would not. This is in fact the most controversial question. Serum CT is a useful marker for C-cell disease and correlates well with tumour burden. MTC accounts for only $5 \%$ of thyroid malignancies; however, recent reports show that the prevalence of MTC ranges from 0.4 to $1.4 \%$ in unselected patients with nodular thyroid disease. Data from non-randomised, prospective studies, mostly from European countries, suggest that routine CT measurement can detect early and unsuspected MTC. ${ }^{28}$ Early diagnosis and prompt thyroidectomy result in decreased morbidity and increased survival. However, there seems to be no consensus on this issue. Outside Europe, the enthusiasm for ordering routine CT has not been high except for a recent publication suggesting cost-effectiveness. ${ }^{44}$ The AACE/AME guidelines do not endorse routine CT measurement, recommending the test only if FNA is suspicious for MTC or family history is positive for MTC/MEN2. The ATA guidelines do not recommend routine $\mathrm{CT}$ measurement. The ETA recommends $\mathrm{CT}$ measurement in the initial diagnostic evaluation of thyroid nodules. 
Recent expert opinion underlines this difference in practice on opposite sides of the Atlantic: Borget et al., writing from France, state that "based on their assumption, plasma CT determination in the assessment of thyroid nodule patient would appear to be highly favourable compared with a number of other accepted health interventions" ${ }^{45}$ By contrast, Podak and Burman, writing from the US, observe that "the issue of CT testing in patients with thyroid disease remains controversial. It does not seem that the use of basal CT levels in the routine screening of patients with nodular thyroid disease is warranted without the ability to use gastrin stimulation as a confirmatory test". ${ }^{46}$ Thus, European thyroid specialists seem to acknowledge this ongoing controversy in thyroid practice, with $49 \%$ using and $43 \%$ not using routine CT measurement. However, it is it surprising that as many as $43 \%$ do not order CT measurement, considering that the overwhelming majority of them today are likely practising in Europe. Therefore, apparently despite the recommendation from the ETA for routine CT determination, many members still consider this issue unresolved. The positive predictive value of routine CT measurements for medullary thyroid carcinoma in patients with thyroid nodules ranges from 10 to $40 \%$ in most studies and is $>90 \%$ in two studies from one group. ${ }^{47}$ Recent studies have shown that the different CT assays have different reference ranges, that the threshold should in fact be 20 instead of $5 \mathrm{pg} / \mathrm{ml}$, as used in many previous studies, that CT levels are influenced by sex, body mass index (BMI) and age and that alcohol and smoking are associated with falsely elevated CT levels. ${ }^{48}$

It is obviously difficult to describe the diagnostic work-up of a patient with a thyroid nodule in a uniformly applicable algorithm. An attempt at an overview that tries to provide an integrated view of the diagnostic approaches for the diagnostic work-up of a patient with a thyroid nodule is described in Figure 2. The clinical work-up of a patient with a thyroid nodule should always be based on the assessment of possible predictors of malignancy (see Table 3) and the assessment of symptoms of hyperthyroidism.
The thyroid nodule guidelines obviously provide useful information and recommendations for practice, and have a positive impact on patient care. However, guidelines should be considered as suggestions rather than a rigid formula for practice. We always have to rely on the art of practical medicine. The arbitrary application of guidelines to the individual patient can lead to problems for the individual patient. The recent thyroid guidelines underscore regional practice differences based partly on different disease epidemiologies, but they also illustrate many similarities. With further accumulating evidence, these guidelines will need revision and updating.

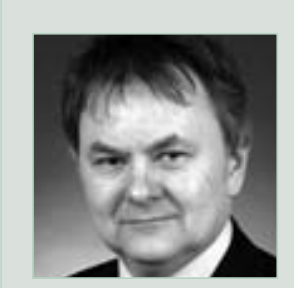

Ralf Paschke is a Professor of Internal Medicine and Endocrinology at the University of Leipzig. He headed the Department of Internal Medicine III for eight years. His major research interests include the thyroid-stimulating hormone (TSH) receptor, the genetics of goitre and thyroid nodules and hyperthyroidism. He hosted the 2007 annual meeting of the European Thyroid Association (ETA) in Leipzig and has served on the Editorial Boards of the Journal of Clinical Endocrinology and Metabolism, Thyroid and Molecular and Cellular Endocrinology.

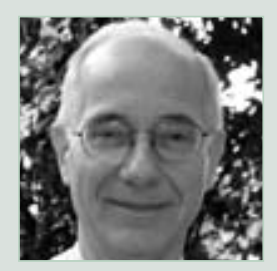

Enrico Papini is Head of the Department of Endocrine and Metabolic Diseases at the Ospedale Regina Apostolorum, Albano in Rome and a Professor of Endocrinology at the University of Rome 'La Sapienza' Medical School. His main areas of clinical and research interest include thyroid cancer and nodular goitre, the thyroid gland and type 2 diabetes. Professor Papini is Past President of the Italian Association of Clinical Endocrinologists (AME).

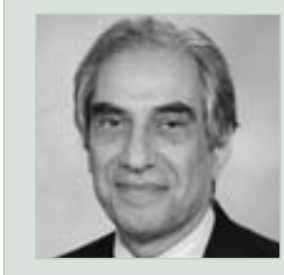

Hossein Gharib is a Professor of Medicine in the Division of Endocrinology, Diabetes, Metabolism and Nutrition at the Mayo Clinic College of Medicine in Rochester. He is also President of the American College of Endocrinology (ACE). An international authority on thyroid disorders, he has lectured at over 250 national and international meetings and has authored or co-authored more than 250 academic papers, including peer-reviewed journal articles, scientific meeting abstracts and book chapters.
1. Brander A, Viikinkoski P, Tuuhea J, et al., J Clin Ultrasound, 1992;20:37-42.

2. Ezzat S, Sarti DA, Cain DR, Braunstein GD, Arch Intern Med, 1994;154:1838-40.

3. Mortensen JD, Woolner LB, Bennett WA, J Clin Endocrinol Metab, 1955;15:1270-80.

4. Volzke H, Ludemann J, Robinson DM, et al., Thyroid, 2003;13:803-10.

5. Krohn K, Fuhrer D, Bayer Y, et al., Endocr Rev, 2005:26:504-24.

6. Krohn K, et al., Nat Clin Pract Endocrinol Metab, 2007;3:713-20.

7. Nagataki S, Nystrom E, Thyroid, 2002;12:889-96.

8. Davies L, Welch HG, JAMA, 2006;295:2164-7.

9. Colonna M, Guizard AV, Schvartz C, et al., Eur I Cancer 2007:43:891-900.

10. Krebs in Deutschland, 2006, Gesellschaft der epidemiologischen Krebsregister in Deutschland e.V.(GEKID) in Zusammenarbeit mit dem Robert Koch Institut (RKI).

11. Harach HR, Franssila KO, Wasenius VM, Cancer, 1985;56:531-8.

12. Brauer VF, Hentschel B, Paschke R, Dtsch Med Wochenschr, 2003;128:2381-7.

13. Lang W, Borrusch H, Bauer L, Am I Clin Pathol, 1988;90: 72-6.

14. Martinez-Tello FJ, Martinez-Cabruja R, Fernandez-Martin J, et al., Cancer, 1993;71:4022-9.

15. Roti E, Rossi R, Trasforini G, et al., J Clin Endocrinol Metab, 2006:91:2171-8.

16. Knudsen N, Perrild $\mathrm{H}$, Christiansen $\mathrm{E}$, et al., Eur J Endocrinol, 2000;142:224-30.
17. Belfiore A, La Rosa GL, Padova G, et al., Cancer, 1987;60:3096-3102

18. Bahre M, Hilgers R, Lindemann C, Emrich D,Acta Endocrinol (Copenh), 1988;117:145-53.

19. Krohn K, Wohlgemuth $\mathrm{S}$, Gerber $\mathrm{H}$, Paschke $\mathrm{R}$, J Pathol, 2000;192:37-42.

20. Laurberg P, Pedersen KM, Vestergaard H, Sigurdsson $G$, J Intern Med, 1991;229:415-20.

21. Emrich D, Erlenmaier U, Pohl M, Luig H, Eur J Nucl Med 1993:20:410-14.

22. Bennedbaek FN, Perrild $\mathrm{H}$, Hegedus L, Clin Endocrinol (Oxf), 1999;50:357-63.

23. Bennedbaek FN, Hegedus L, J Clin Endocrinol Metab, 2000;85:2493-8.

24. Fuhrer D, Mugge C, Paschke R, Exp Clin Endocrinol Diabetes, 2005;113:152-9.

25. Paschke R, Reiners C, Fuhrer D, et al., Dtsch Med Wochensch 2005;130:1831-6.

26. American Association of Clinical Endocrinologists and Associazione Medici Endocrinologi, Endocr Pract, 2006; 12:63-102.

27. Cooper DS, Doherty GM, Haugen BR, et al., Thyroid, 2006; 16:109-42.

28. Pacini $F$, Schlumberger $M$, Dralle $H$, et al., Eur J Endocrinol, 2006; 154:787-803.

29. Gharib H, Papini E, Paschke R, Eur J Endocrinol, 2008:159:493-505

30. Diehl LA, Garcia V, Bonnema SJ, et al., J Clin Endocrinol Metab, 2005;90:117-23.

31. Marqusee $\mathrm{E}$, Benson $\mathrm{CB}$, Frates $\mathrm{MC}$, et al., Ann Intern Med, 2000;133:696-700.
32. Tan GH, Gharib H, Reading CC, Arch Intern Med, 1995:155:2418-23.

33. Hagag P, Strauss S, Weiss M, Thyroid, 1998:8:989-95.

34. Frates MC, Benson CB, Charboneau JW, et al., Radiology, 2005:237:794-800.

35. Frates $\mathrm{MC}$, Benson $\mathrm{CB}$, Doubilet PM, et al., J Clin Endocrinol Metab, 2006;91:3411-17

36. Rago T, Di Coscio G, Basolo F, et al., Clin Endocrinol (Oxf), 2007;66:13-20.

37. Pacini F, Burroni L, Ciuoli C, et al., Eur I Nucl Med Mol Imaging, 2004:31:1443-9.

38. Gharib H, Papini E, Endocrinol Metab Clin North Am, 2007:36:707-35, vi.

39. Wiersinga WM, Eur J Endocrinol, 1995;132:661-2.

40. Lucas A, Llatjos M, Salinas I, et al., Eur J Endocrinol, 1995:132:677-80.

41. Chehade JM, Silverberg AB, Kim J, et al., Endocr Pract, 2001;7:237-43.

42. Richter B, Neises G, Clar C, Endocrinol Metab Clin North Am, 2002;31:699-722.

43. Paphavasit A, Thompson GB, Hay ID, et al., Arch Surg, 1997;132:674-8

44. Cheung K, et al., J Clin Endocrinol Metab, 2008;93: 2173-80

45. Borget I, De Pouvourville G, Schlumberger M, I Clin Endocrinol Metab, 2007;92:425-7.

46. Hodak SP, Burman KD, J Clin Endocrinol Metab, 2004;89:511-14

47. Costante G, Durante C, Francis Z, et al., Nat Clin Pract Endocrinol Metab, 2009:5:35-44.

48. d'Herbomez M, et al., Eur J Endocrinol, 2007;157:749-55. 